\title{
Adopting Electronic Business in Ghana: Story of the Hospitality Industry
}

\author{
Nana Yaw \\ Asabere \\ Computer Science \\ Department \\ School of Applied \\ Science and Arts \\ Accra Polytechnic, \\ Accra, Ghana
}

\author{
Vida Doku \\ Hotel, Catering and \\ Institutional Management \\ Department \\ School of Applied \\ Science and Arts \\ Accra Polytechnic, \\ Accra, Ghana
}

\author{
Simonov Kusi- \\ Sarpong \\ School of Management \\ Science and Engineering \\ Dalian University of \\ Technology, Dalian \\ 116024, Liaoning \\ Province, P.R. China
}

\author{
David Oppong \\ Department of \\ Purchasing and \\ Supply, School of \\ Business and \\ Management Studies \\ Accra Polytechnic, \\ Accra, Ghana
}

\begin{abstract}
Electronic business (E-business) is a process of conducting business through the use of Information and Communication Technology (ICT), specifically the Internet. As a result of the current proliferation of ICT, e-business as well as other electronic applications and activities have globally sprung up and many companies and organizations in Ghana are realizing their importance and necessity. Over the past few years, the hospitality standards for hotels, restaurants and tourism operations in Ghana have improved. This has enabled the harmonization of hotel and restaurant licensing standards in West Africa, which is part of the Revised Treaty of the Economic Community of West African States (ECOWAS). Using relevant literature, this paper describes the importance of adopting e-business in the hospitality industry of Ghana with a focus on its benefits and challenges in such an industry. Additionally, the paper ascertains the relevance of the Technology Acceptance Model 2 (TAM2) in the hospitality of Ghana when adopting e-business.
\end{abstract}

\section{General Terms}

E-Business, Hospitality Industry

\section{Keywords}

Adoption, ICT, E-business, Hospitality Industry, Technology Acceptance Model (TAM).

\section{INTRODUCTION}

Information and Communications Technology (ICT) involves the use of computer hardware, software and telecommunication devices to store, manipulate, convert, protect, send and receive data [1]. ICTs are necessary components of business culture. Nowadays, the use of ICTs is no more a distinctive characteristic by itself. Only an effective and efficient usage of ICT helps organizations and individuals gain competitive advantages [2].

The availability of technological and computing devices has made it easier for professionals to collect, store, manipulate and share data and information both individually and within organizations, small and large, public and private. ICT has become an integral part of our daily activities and currently has an impact on the way we live, work and play to an extent that sometimes we barely notice its effect [3]. The tremendous growth in the use of networked computers is one of the most substantial trends in modern computing and ICT. Though interconnection of computers in itself is not new, the application of networking is realizing a dramatic increase such that it is now one of the major issues in computer and Information Technology [4].
One important aspect of ICT is the Internet. Globally, the Internet is used by many individuals and organizations in different societies mainly for sharing information and ideas. The Internet has transformed the computer and communications world like never before. The original invention of the telegraph, radio and computer set the stage for this extraordinary incorporation of capabilities. Some features of the Internet include: a mechanism for information dissemination, a medium for collaboration between individuals and their computers without regard for geographic location and a world-wide broadcasting capability [5]. In terms of sustained investment, commitment to research and development of information structure, various organizations and individuals have used the Internet to benefit from such activities and opportunities. The "commercialization of the Internet" started through three concurrent events. These events involved: $(i)$ the removal of restrictions by the National Science Foundation (NSF) over the use of the Internet for commercial purposes (ii) the founding of Netscape and (iii) the rapid entry of tens of thousands, perhaps hundreds of thousands of firms into commercial ventures using technologies that employ the suite of TCP/IP standards [6]. These events have now turned every PC into a potential client for Internet applications and introduced electronic applications such as e-business, e-procurement and ecommerce.

Due to the commercialization of the internet, many firms in both developing and developed countries are undergoing ebusiness activities on a daily basis. E-business is defined as the use of electronic means to produce, distribute, market and sell/deliver goods and services. Amit and Zott [7] defined an e-business firm as one that derives a significant proportion (at least $10 \%$ ) of its revenues from transactions conducted over the Internet. Amit and Zott [7] further emphasized that the definition of an e-business is quite broad. It includes, for example, Internet Service Providers (ISPs) and companies that have not aligned all of their internal business processes with the Internet but use the Internet solely as a sales channel. On the other hand, e-business doesn't include providers of Internet related hardware or software, that is, firms that facilitate e-business but that do not engage in the activity themselves (e.g., a backbone switch manufacturer) [7].

E-business usually implies a rethinking of business models, the network and system infrastructure. Therefore, only businesses with access to significant e-business competency can expect to succeed with their efforts [8][9]. Organizations adopt e-business for several reasons and perceived benefits. Some of these benefits include better management of information, lower transaction costs, better channel 
partnership, better integration of suppliers and vendors, better market understanding and expanded geographical coverage [10].

The hospitality industry is at the forefront of the whole tourism sector and it is especially delicate to the everincreasing competitive pressure and to the growing needs for more effective operational and control tools. The help that can be given by ICTs is consequently much sought-after and is seen as capable of providing new prospects for business development [2]. In hotels, some functions which can be performed with computers through the aid of management softwares include: data, yield and reservation management, accounting for guests, forecasting guest demand for reservations and management of guest services [3][11]. The contribution of the hospitality and tourism industry to the overall growth of the economy of Ghana cannot be overemphasized [12][13[14]. For the hospitality industry in Ghana to succeed, the requirements for efficient and responsive hotel subsectors which incorporate current trends of business and customer service cannot be overlooked. The current availability of efficient smart services provide attributable grounds for e-business which introduces innovative and larger prospects for firms, industry and the country (Ghana) as a whole. This has necessitated the availability of knowledge through research. Skepticism or uncertainty about e-business has always been an obstruction to realizing the benefits inherent in its adoption especially in the developing countries where Information and Communication Technology (ICT) is yet to see its best level of proliferation.

In the opinion of many organizations, the use of its existing structures, systems and methods help managers and operators remain in their comfort zone without many challenges. Nevertheless, e-business presents a more distinct option and its adoption introduces more benefits and provides global competitiveness for modern business. Upon realizing the importance of e-business in organizations through relevant literature, this paper moves a step further by assessing the benefits as well as challenges of e-business adoption in the hospitality industry in Ghana, in order to identify the factors impeding its adoption. Additionally, this paper assesses two Technology Acceptance Models (TAM and TAM2) with a focus on TAM 2 and its relevance to e-business adoption in the hospitality industry of Ghana.

The rest of the paper is organized as follows: A Review of Literature is presented in Section 2. Section 3 presents a discussion on the Benefits and Challenges of E-Business with a focus on the Hospitality Industry in Ghana. Section 4 elaborates on Research Discussion and Section 5 finally concludes the paper with some Recommendations and outlines some Future Work.

\section{LITERATURE REVIEW}

This Section of the paper reviews relevant literature pertaining to the subject matter. Initially, the evolution of e-business and e-business concepts and models are reviewed. Then, the next review elaborates on e-business adoption and finally a brief description of the hospitality industry in Ghana is also presented.

\subsection{The Evolution of E-Business}

With the rapid growth of ICT and the Internet, nowadays, organizations have the ability to conduct businesses beyond traditional procedures and can further expand their activities to other geographical locations. Usually, organization that can adapt and control the potential of the internet and its related technology will find success in attracting new customers, retaining customers, operations, attracting new partners, streamlining channels and improving productivity [15]. The evolution of e-business has taken several stages. As technology progressions have transpired, e-business functions and transactions have improved as well.

E-Business can be classified into three (3) generations. The first generation was classified as efforts to conduct e-business prior to the advent of the Internet [15]. Owens [16] asserted that in the second generation of e-business evolution, most businesses progressed in e-commerce (buying and selling using the internet) i.e. most business started to conduct sales transactions electronically. Although, the second generation was an improvement in comparison to the first, e-commerce needed to be integrated with other organizational functions so that the third generation of e-business could evolve. The current generation of e-business evolution (stage 3) integrates all the functions of an organization with electronic sales data [15]. This has resulted in the inclusion of electronic sales connections to other parts of an organization that relate externally to customers, suppliers and an ultimately improved supply chain and internally to marketing, customer service, finance, staffing and fulfillment [16]. Organizations that realize how important effective integration of systems and process are usually gain significant and competitive advantages. Quite often, many organizations improve their position through effective use of e-marketing as part of the ebusiness process [15].

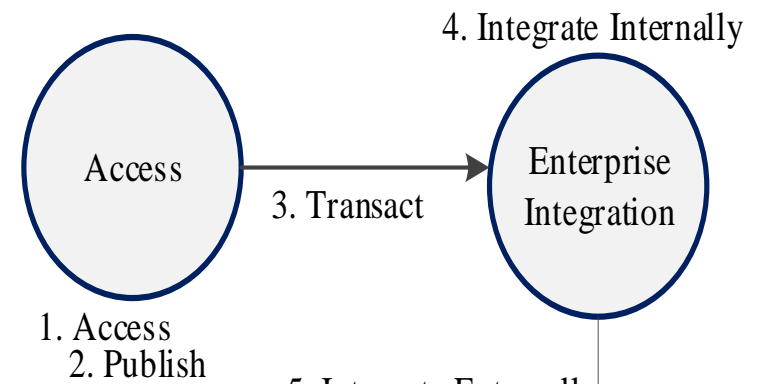

2. Publish

\section{Integrate Externally}

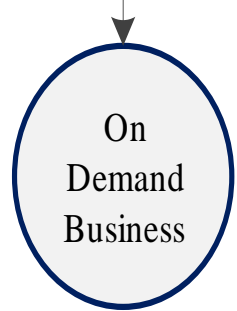

Fig. 1: Evolution Phases of E-Business Adoption

\subsection{E-Business Concepts and Models}

With reference to the enterprise level business solutions and infrastructures over the Internet, e-business has become a popular term with high exposure in the modern society. Nevertheless, in retrospect, its original initiation in the midnineties did not cause a significant impression. Rather, as shown in Figure 1, e-business started as a common technical innovation aiming at supporting simple Internet browsing and interaction utilizing Hyper Text Transfer Protocol (HTTP) [17]. In order to allow global access, companies publish static information (e.g., business name, address, contact information, company history) on their Hypertext Markup Language (HTML) homepages on the Internet. Enterprises did not stop at static information sharing; instead, they tried to explore the Internet as a new business medium to conduct business activities. Soon afterwards, online transactions, such as online payment, online auction and online shopping were 


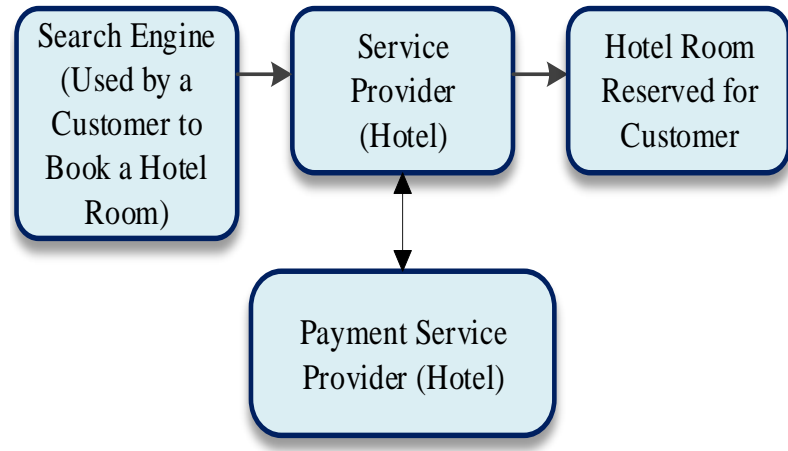

Fig. 2: An E-Business Snapshot of a Hotel Service Provision

introduced [17]. The beginning of the $21 \mathrm{st}$ century has witnessed advancements of e-business which has caught significant attention of various occupations and the society in general. Nowadays, the business world is facing an electronic information revolution, which has introduced the term "ebusiness". The term e-business was coined to represent enterprise-level business transformation. In this information revolution, enterprise-internal information transformation has great importance in expediting resource utilization and management effectively and efficiently. Meanwhile, interenterprise communications and interactions have become unavoidable [17]. A modern enterprise can no longer stand alone; instead, it has to constantly interact with and rely on its interrelated enterprises, its suppliers, and its clients, thus establishing a functioning enterprise-level service chain. This level of e-business is called enterprise conformity. After these enterprises are synergistically integrated with each other, their mutual interdependencies become remarkable. To ensure that this sophisticated enterprise service chain adapts itself with stochastic adjustments, when the market fluctuates, remains a big challenge [17].

Figure 2 shows a snapshot of an on-demand business model. Assume that a user discovers an interesting Hotel in which he/she would like to book a room from an online search engine, then clicks the associated link to connect to the corresponding Hotel. After filling an online booking form with payment information (e.g., credit card number, name shown on the card and expiration date), the user sends the request to the Hotel. The Hotel then dynamically connects to the corresponding payment service provider (e.g., the credit card company) to perform a real-time transaction and acknowledges the payment of the customer/user for onward reservation of an available room. This simple example shows that the modern business models require seamless runtime interaction and collaboration among suppliers, partners, and customers on an on-demand basis. The approach used to conducting electronic business on the Internet is called an ebusiness model. E-business transactions take place between two major entities, namely, businesses and consumers. All ebusiness activities happen within the framework of two main types of business relationships: $(i)$ the exchange of products and services between businesses (business-to-business, or B2B) and (ii) the exchange of products and services with consumers (business-to-consumer, or B2C), these are depicted in Figure 3 [18]. The primary difference between B2B and $\mathrm{B} 2 \mathrm{C}$ are the customers. B2B customers are other businesses while $\mathrm{B} 2 \mathrm{C}$ markets to consumers. Overall, B2B relations are more complex and have higher security needs. Additionally, $\mathrm{B} 2 \mathrm{~B}$ is the dominant e-business force, representing 80 percent of all online business. Figure 3 illustrates all the e-business models, these include: Business-to-Business (B2B), Businessto-Consumer (B2C), Consumer-to Consumer (C2C), and Consumer-to-Business (C2B) [18].

Figure 4 illustrates an internet connection of some business organizations related to the hospitality industry. These business organizations consist of Airport, Hotel, Tourist Site, Telecommunications and Train Station. Through such an internet connection these organizations are adopting a B2B ebusiness model and thus conducting external business processes and activities. Additionally, Figure 5 depicts the internet connection between four major departments of a Hotel, namely, Housekeeping, Front Office, Food and Beverage (F \& B) Services and Food Production. Figure 5 depicts that e-business can be practiced and adopted internally by major and relevant departments of organizations in order to acquire important communication and output benefits.

\subsection{E-Business Adoption}

The critical success factors in the adoption of e-business in organizations are recognized as: combining e-business knowledge, value proposition and delivery measurement, customer satisfaction and retention, monitoring internal processes and competitor activity and finally building trust [19]. Adoption of e-business is anticipated to result in generation of new forms of immediate value for organizations. In order to appreciate the full advantages of ebusiness solutions, organizations need to identify the critical success factors [19]. Success is defined in the Chambers Dictionary [20] as 'having achieved the desired results, effects or outcomes. Critical success factors are defined as those few key areas where things must go right for business to prosper and grow [21]. It has been advocated that management needs to pay attention to these areas, and make performance measures integral to the definition of critical success factors in order to prevent poor enterprise performance [22] Performance is signified by the achievement of progress towards the desired state. Strassman [23] summarized this argument very clearly in stating that "You can't measure what

\begin{tabular}{|ll|}
\hline $\begin{array}{l}\text { E-Business } \\
\text { Model }\end{array}$ & Definition \\
\hline $\begin{array}{l}\text { Business-to- } \\
\text { Business (B2B) }\end{array}$ & $\begin{array}{l}\text { Applies to businesses buying from and selling to } \\
\text { each other over the Internet. }\end{array}$ \\
\hline $\begin{array}{l}\text { Business-to- } \\
\text { Consumer (B2C) }\end{array}$ & $\begin{array}{l}\text { Applies to any business that sells its products or } \\
\text { services to the consumers over the Internet. }\end{array}$ \\
\hline $\begin{array}{l}\text { Consumer-to- } \\
\text { Consumer (C2C) }\end{array}$ & $\begin{array}{l}\text { Applies to sites primarily offering goods and services } \\
\text { to assist consumers interacting with each other over } \\
\text { the Internet. }\end{array}$ \\
\hline Consumer-to- & $\begin{array}{l}\text { Applies to any consumer that sells a products or } \\
\text { service to a business over the Internet. }\end{array}$ \\
\hline
\end{tabular}

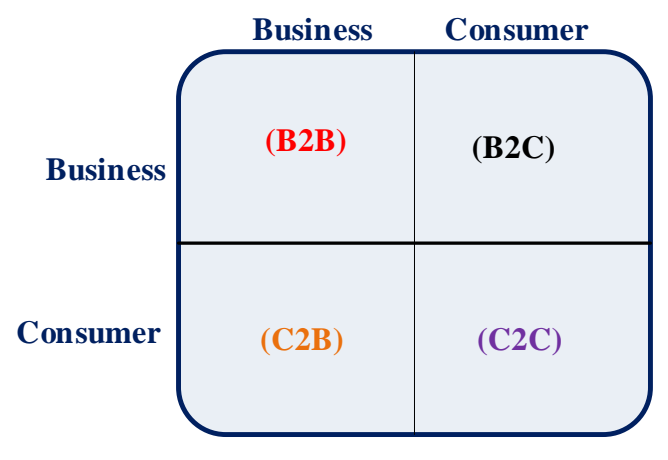

Fig. 3: Basic E-Business Models 
is not defined". Additionally, "You also cannot tell whether you have improved something, if you have not measured its performance" [23].

In the framework of e-business adoption, Porter [24] emphasized that in order to participate in the 'new economy' marketplaces successfully, and thus gain competitive advantages, organizations should build on their proven principles of effective strategy and integrating e-business as a complement to traditional methods of competing. More precisely, the key to e-business success is to complement an organization's specific business knowledge with the necessary awareness of the new opportunities created by e-business [25]. Central and axiomatic to this perspective is that adoption of e-business should be suitable, relevant, value adding, and operationally as well as strategically viable for an organization instead of being a result of apprehensive compliance [19].

Recent literature addressing the management of e-business highlights the diversity of factors that contribute to success or failure of e-business adoption. For example, Butler [26] emphasized that e-business success depends on a company's commitment to e-business leadership/management, roles and responsibilities, cross-functional interdependencies, budget matters and management structure. This implies that executives need to have a solid understanding of the rapidly changing capabilities for technology, and communicate the value of e-business throughout the organization [19]. While some e-business initiatives are managed successfully, many

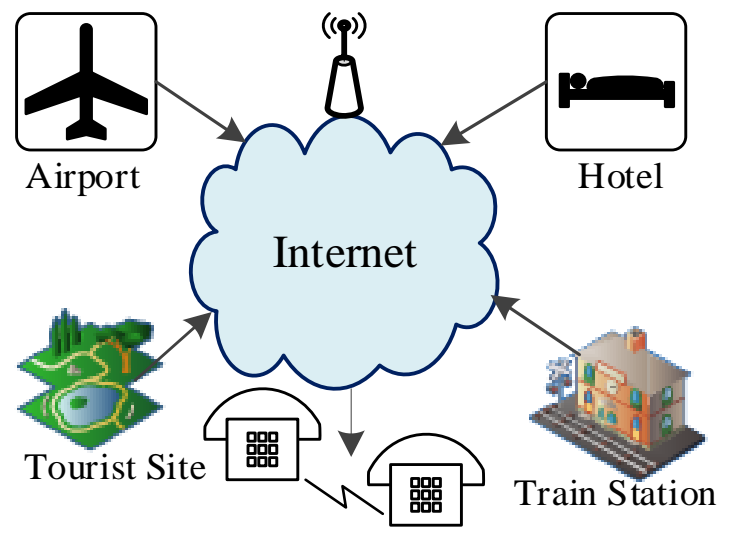

Telecommunications

Fig. 4: Some Business Organizations Related to the Hospitality Industry Connected together Using EBusiness

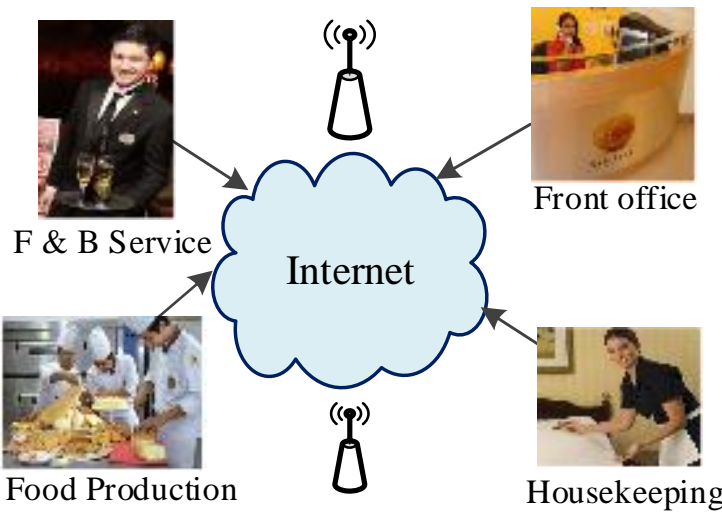

Fig. 5: Some Major Department of a Hotel adopting EBusiness businesses are challenged with various adoption issues that originate from a combination of imprecise business vision for e-business and lack of technological expertise [19]. Usually, poor business performance and repetitive patterns of existing behavior are signals and symptoms of failure [27]. For instance, according to Bowde et al. [28], the most important inhibiting factors creating difficulties for organizations with their e-business initiatives are identified as: low customer use of e-business solutions, uncertainty of financial benefits, limited size of target market, lack of time to start new projects and high costs of computing technology. Similarly, Kanter [29] in an e-culture survey studying both "dot.coms" and established organizations showed that organizations more than 20 years old face fewer market place and technology barriers than younger ones do, but they face many internal barriers, from decision-maker uncertainty to divisional rivalry. Kanter's [29] research study indicated that when established organizations fail to adopt e-business successfully, causes are not Internet or e-business specific, but rather from organizational issues like top management/leadership shortsightedness and longstanding internal barriers. Therefore, the biggest problem established organizations are facing when considering e-business adoption is organizational change [19]. When organizations attempt and try to manage e-business adoption and transformation successfully, attention is generally paid exclusively to technology, rather than business processes and e-business readiness throughout the value chain [30].

Specifically, lagging practices of underperforming organizations are based on technology focus rather than rationalization of e-business projects as 'pilot' or 'learning' processes. For instance, organizations that were identified as laggards in e-business adoption inclined to assign responsibility for e-business development to the IT/ICT department. According to Slywotzky and Morisson [31] many senior executives of organizations equate 'going digital' with specific technology (e.g. Enterprise Resource Planning (ERP) systems, Internet)), instead of using digital technologies to expand their organization's strategic options. Going digital or an organization being digitally inclined is about serving customers, creating unique value propositions, leveraging talent, achieving high order of magnitude improvements in productivity and increasing and protecting profits [31].

Economic issues of organizations and the country as a whole, further present additional impediments to successful ebusiness adoption. The high risk and cost associated with ebusiness projects has made many senior executives organizations have a rethink and consequently rate e-business as a medium or low priority and not fundamental to their business [32]. Furthermore, an important impediment identified in the literature is absence of a well-defined ebusiness strategy that supports and is supported by a welldefined business strategy [19].

\subsection{Brief Description of the Tourism and Hospitality Industry in Ghana}

Since the late 1980s, the tourism industry has received considerable attention in the economic development strategy of Ghana. The number of tourist arrivals and amount of tourists' expenditure have progressively increased, while both public and private investment activity in various tourism subsectors have expanded [12]. The Government of Ghana established a Ministry of Tourism (MoT) in 1993 to emphasize its commitment to tourism development. With assistance from the United Nations Development Programme (UNDP) and the World Tourism Organization (WTO), the 
MoT prepared a 15-Year Tourism Development Plan for the period 1996 to 2010 [12]. Similar to most African countries, attempts to develop a practical tourism industry in Ghana can be traced to the early part of the post-independence period [12]. The tourism industry has contributed significantly to the country's economy, particularly in recent times, through its continuous demonstration and potential as a key driver of growth. For example, between 2000 and 2005, visitor arrivals and spending increased by 46 per cent and 68 per cent respectively [14]. The industry is currently the third largest foreign exchange earner after merchandise exports and remittances from abroad and has become one of the most important and fastest growing sectors of the Ghanaian economy. Tourism receipts were forecasted to reach $\$ 1.5$ billion by the end of 2007 [14]. International tourist arrivals and receipts have shown steady and positive trends since 1991, except for a slight dip in arrivals in 2005 . Tourist arrivals significantly increased from 172,000 in 1991 to 429,000 in 2005 [14]. According to [14], a close look at the origination of tourists in Ghana from thirteen generating markets indicates that there were consistent upward trends in arrivals irrespective of origin between 1991 and 2005. Ghana is gradually shifting its attention from primary commodities to a market-oriented economy with emphasis on tourism and the hospitality industry in general. It is widely recognized that the hospitality industry is directly linked to the country's cultural, economic and intellectual potential. Therefore, the hospitality industry must be managed properly to meet international standards in order to realize the full benefits that the industry offers [13]. Businesses are increasingly being asked to shoulder responsibility for their social, ethical and environmental impact, with this pressure particularly felt in consumer-facing industries [7][17][18][19]. Since the hospitality industry is being packaged by the Government of Ghana as the next major source of foreign exchange earner, it is very important to scientifically ascertain the governance practices of the hospitality industry by comparing it to best practices around the world. The main reason for the study in [13] was that no scientific study had been carried out in this area to ascertain the industry's governance practices of 3-Star and 4-Star Hotels. Furthermore, because the hospitality industry is not one of the industries highly regulated by the Government like the financial services industry, the authors in [13] envisaged the necessity to conduct such a study. Ghana is regarded as having improved in hospitality standards for hotels, restaurant, travel and tour operations. Additionally, Ghana has played a leading role in the harmonization of hotel and restaurant licensing standards in West Africa, which is part of the Revised Treaty of the Economic Community of West
African States (ECOWAS). Over the years, the Ghana Tourist Board (GTB now replaced by the GTA - the Ghana Tourism Authority) has teamed up with private sector producers of cleaning detergents to train hotel staff in cleaning and hygiene standards, which has improved the quality standards of facilities [33].

Since the launch of the Tourism Development Plan by the Ministry of Tourism, hotel investment has been buoyant. Hotels in Accra, Ghana and other major cities show annual average occupancy rates of $75 \%$, which is indicative of the vibrant demand and commercial profitability of hotels, particularly those offering international standards [33]. As shown in Table 1, 2005-2010 witnessed improving as well as changing trends in terms of Hotel Star levels in Ghana in relation to their yearly performances. It is also evident from Table 1 that the most dominant star level of Hotels in Ghana is 1-Star and 5-Stars represent the least dominant. It is inevitable that there will be increased competition for existing hotels due to new entrant hotels such as the 5-star Airport City Hotel (Marriott) and eventually the Kempinski Hotel in downtown Accra. This should also lead to a demand-driven increase in visitor arrivals especially for conference and leisure tourism because of the room availability and market visibility of Ghana [33]. The number of airlines flying to Ghana has doubled since 1996 when there were 15 international airlines with scheduled flights to Kotoka International Airport (KIA) and four cargo airlines. In 2012, 30 passenger airlines and six cargo airlines flew to Accra and several more are currently applying for routes, these include: Royal Jordanian, Qatar Airways, Air Namibia, China Eastern Airlines and Air Canada. Passenger numbers have increased from 352,000 in 1996 to over 1.73 million in 2011 [33]. Domestic air services have increased from two routes to four routes. Accra is still the only international air gateway although there are plans to expand the airport in Tamale (Northern Region of Ghana) for international flights and to build a new international airport at Takoradi (Western Region of Ghana). Whilst these developments are mostly driven by demand from the business sector, greater air access opportunities will also benefit the development of leisure tourism [33].

\section{E-BUSINESS BENEFITS AND CHALLENGES}

As e-business improves, organizations will experience benefits and challenges alike. Focusing on the hospitality industry, Table 2 illustrates e-business benefits for an organization [18]. The proliferation of the Internet is forcing organizations to refocus their information systems inside out. A growing number of organizations are already using the

Table 1: Licensed Star Rated Hotels in Ghana between 2005 and 2010

\begin{tabular}{|c|c|c|c|c|c|c|}
\hline \multirow[b]{2}{*}{ Stars } & \multicolumn{6}{|c|}{ Years } \\
\hline & 2005 & 2006 & 2007 & 2008 & 2009 & $2010 *$ \\
\hline 5-Star & 1 & 1 & 1 & 1 & 1 & 1 \\
\hline 4-Star & 4 & 4 & 4 & 4 & 5 & 5 \\
\hline 3-Star & 28 & 30 & 20 & 26 & 17 & 23 \\
\hline 2-Star & 137 & 138 & 133 & 149 & 165 & 163 \\
\hline 1-Star & 154 & 169 & 154 & 188 & 184 & 225 \\
\hline Total Number of Star Hotels & 324 & 342 & 312 & 368 & 372 & 417 \\
\hline
\end{tabular}

*Provisional, Source: Ghana Tourist Authority (GTA) and [33] 
Table 2: E-Business Benefits in the Hospitality Industry

\begin{tabular}{ll}
\hline \hline Factor & Description \\
\hline Increased Customer Loyalty & $\begin{array}{l}\text { Additional channels to contact, respond to, and access various customers/guests helps } \\
\text { contribute to customer/guest loyalty in the hospitality industry. } \\
\text { In the hospitality industry, e-business automates and improves many of the activities that } \\
\text { make up a buying experience and creates convenience for customers/guests. }\end{array}$ \\
Ancreased Convenience & $\begin{array}{l}\text { As result of e-business, organizations in the hospitality industry can operate 24 hours a day, } \\
7 \text { days a week, } 365 \text { days a year. } \\
\text { In the past, customers/guests of hotels, restaurant and tourist sites had to order catalogs or } \\
\text { Improved Information Content } \\
\text { travel to a physical facility before they could compare price and product attributes. } \\
\text { Nowadays, e-business has enabled the presence of electronic catalogs and web pages for } \\
\text { customers/guests with updated information in real-time about goods, services and prices. } \\
\text { The cost of conducting hospitality business on the Internet is substantially smaller than } \\
\text { traditional forms of business correspondence and communication. } \\
\text { Business in the hospitality industry, both small and large, can reach new and innovative } \\
\text { markets worldwide. }\end{array}$ \\
\hline \hline
\end{tabular}

Table 3: E-Business Challenges in the Hospitality Industry

\begin{tabular}{ll}
\hline Factor & Description \\
\hline Providing Security & The Internet provides universal access, but organizations in the hospitality industry must \\
protect their assets against accidental or malicious misuse. System security, however, must \\
not create prohibitive complexity or reduce flexibility. The information of customers/guests \\
also need to be protected from internal and external misuse. Privacy systems should \\
safeguard the personal information critical to building sites that satisfy customer and \\
business needs. A serious deficiency arises from the use of the Internet as a marketing \\
means. Sixty percent of Internet users do not trust the Internet as a payment channel. The \\
makes purchases via the Internet for hospitality services unsafe for many people. This issue \\
affects both the hospitality business and the consumer. Nevertheless, with encryption, \\
authentication and the development of secure websites, security is becoming less of a \\
constraint for e-businesses in the hospitality industry.
\end{tabular}

Adhering to Taxation Rules

The taxation level of the e-business is not the same as that of traditional businesses. While taxation should not dampen consumers from using electronic purchasing channels, it should not favor Internet purchases over store purchases either. Instead, the hospitality industry should design a tax policy to a level playing field for traditional retail businesses, mail-order companies, and Internet-based merchants.

Increasing Liability

E-business in the hospitality industry exposes suppliers to unknown burdens because the Internet commerce law is vaguely defined and differs from country to country. The Internet and its use in e-business have raised many ethical, social and political issues, such as identity theft and information manipulation.

Protecting Customers

Consumers in the hospitality industry must be protected against illegal or harmful goods and services, insufficient information about goods and services or their suppliers, unsolicited goods and communication, invasion of privacy and cyber fraud.

Leveraging Existing Systems Nowadays, most organizations in the hospitality industry use ICT for business environments such as customer service, order management, billing, marketing, inventory and distribution. The Internet represents an alternative and complementary way to do business, but it is vital that e-business systems integrate existing non-ICT systems in a manner that avoids duplicating functionality for the maintenance of performance, reliability and usability.

Internet to automate customer service, sell products, streamline their business processes, procure materials and create new revenue streams. Although the benefits of ebusiness systems are attractive, developing, deploying and managing these systems is not always easy. Unfortunately, ebusiness is not something a business can just go out and buy. Table 3 depicts the challenges of e-business with a focus on the hospitality industry [18].

\section{RESEARCH DISCUSSION}

In order to obtain a general view of the e-business adoption phenomenon, the global academic and research community has focused a lot of attention on the analysis of the e-business adoption process as well as on the examination/exploration of the substantial factors that affect the specific process [34]. An important factor of e-business adoption is that organizations need to design a model for user acceptance of technology through the theoretically extended TAM2 [36]. This paper describes the importance of TAM and TAM2 and their relevance in the hospitality industry of Ghana towards ebusiness adoption [36]. Low usage of installed systems has been identified as a major factor underlying the "productivity paradox" surrounding uninspiring returns from organizational investments in ICT [37]. 


\subsection{Technology Acceptance Model (TAM)}

ICT adoption and use in workplaces and organizations remains a central concern of information systems research and practice. Despite impressive advances in software and hardware capabilities, the troubling problem of underutilization by the human organizations remains a highpriority research issue [36]. Substantial progress has been made over the last decade in explaining and predicting user acceptance of ICT at work. In particular, significant theoretical and empirical support has accumulated in favor of the Technology Acceptance Model (TAM) [35]. Numerous empirical studies have found that TAM consistently explains a substantial proportion of the variance (typically about $40 \%$ ) in usage intentions and behavior, and that TAM compares favorably with alternative models such as the Theory of Reasoned Action (TRA) and the Theory of Planned Behavior (TPB) [36][38].

TAM hypothesizes that an individual's behavioral intention to use a system is determined by two beliefs: perceived usefulness, defined as the extent to which a person believes that using the system will enhance his or her job performance, and perceived ease of use, defined as the extent to which a person believes that using the system will be free of effort. TAM posits that the effects of external variables (e.g. system characteristics, development processes, training etc.) on intention to use are mediated by perceived usefulness and perceived ease of use [35][36].

\subsection{Technology Acceptance Model 2 (TAM2)}

According to TAM [35], perceived usefulness is also influenced by perceived ease of use because, other things being equal, the easier the system is to use the more useful it can be. Using TAM [35] as the starting point, TAM2 [36] integrates additional theoretical concepts spanning social influence processes (subjective norm, voluntariness, and image) job relevance, output quality, result demonstrability, and perceived ease of use. Since TAM2 is an extension of TAM, this paper focuses more on TAM2 (shown in Figure 6) and assess its applicability in the hospitality industry in terms of e-business adoption. Referring to [36], the paper describes each of the above concepts below.

\subsubsection{Social Influence Processes}

TAM2 replicates the influences of three interconnected social forces impinging on an individual facing the opportunity to adopt or reject a new system. These influences are subjective norm, voluntariness and image.

- Subjective Norm - Vanketash and Davis [36] tapped into social influences via subjective norm, defined as a "person's perception that most people who are important to him think he should or should not perform the behavior in question" [39]. The basis for a direct effect of subjective norm on an intention is that people may choose to behave in a particular way, even if they themselves are not favorable towards the behavior or its significances. If they believe one or more important referents think they should, then they are sufficiently motivated to comply with the referents [36].

- Voluntariness and Compliance with Social Influence - TAM2 posits that, in a computer usage context, the direct compliance-based effect of subjective norm on intention over and above perceived usefulness and perceived ease of use will occur in mandatory, but not voluntary, system usage settings. To differentiate between mandatory and voluntary usage settings, TAM2 theorizes voluntariness as a moderating variable, defined as "the extent to which potential adopters perceive the adoption decision to be non-mandatory" [36].

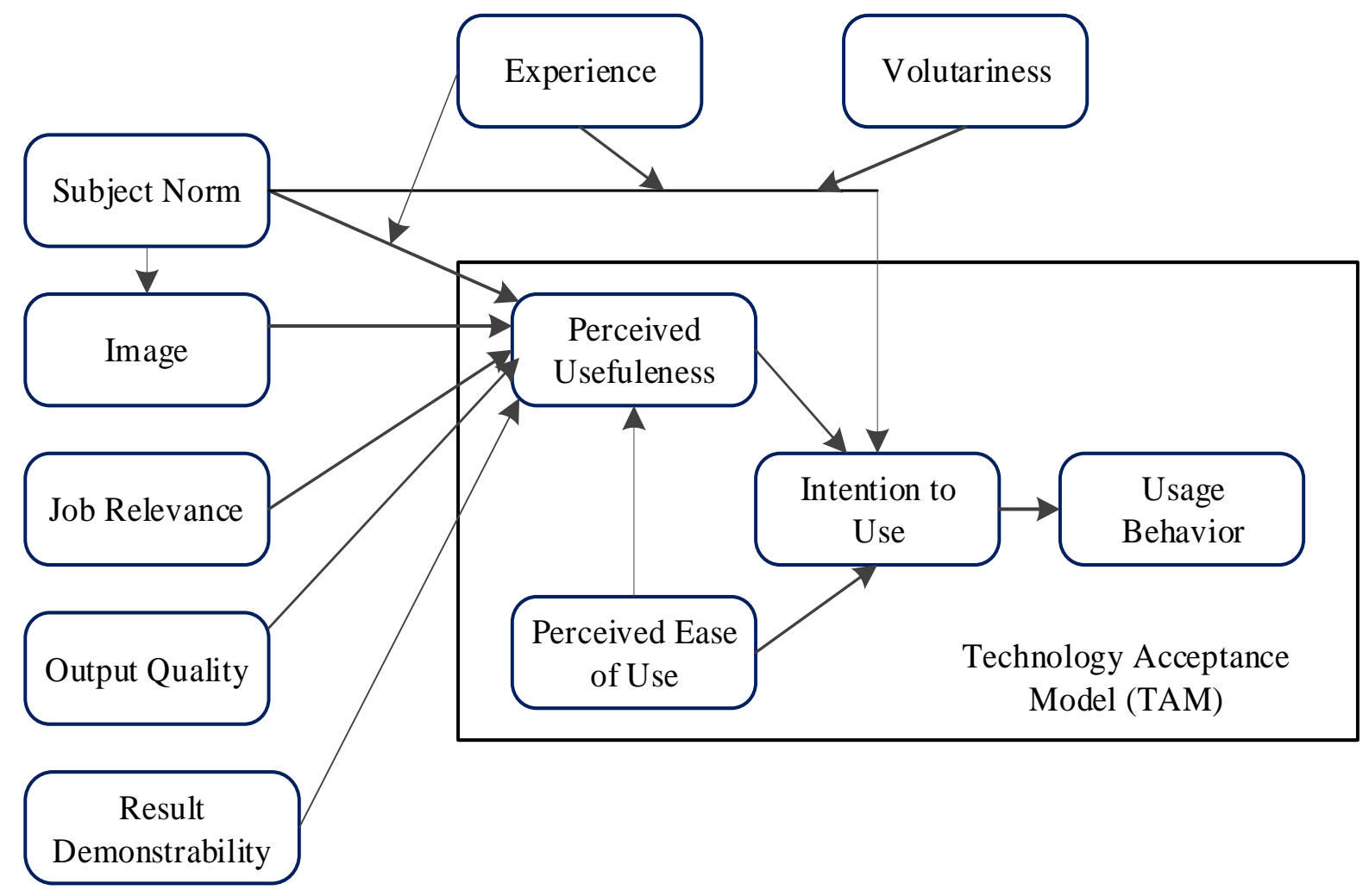

Fig. 6: Technology Acceptance Model 2 (TAM2) 
- Image and Social Influence - In order to establish or maintain a favorable image within a reference group, Individuals often respond to social normative influences [40]. Reflecting from a research on diffusion of innovations, Moore and Benbasat [41] defined image as "the degree to which the use of an innovation is perceived to enhance one's status in one's social system." TAM2 hypothesizes that subjective norm will positively influence image because, if important members of a person's social group at work believe that he or she should behave in a certain way (e.g., using a system), then the person's performance will tend to uplift his or her standing (image) within the group.

\subsubsection{Changes in Social Influence with Experience}

The authors in [36] emphasized that in terms of social influence, organizations should seek answers to the question: How might the effects of these social influence processes (above) change with increasing experience using a target system? There is theory and evidence to suggest that the direct effect of subjective norm on intentions may subside over time with increased system experience. Therefore, TAM2 posits that the direct effect of subjective norm on intentions for mandatory usage contexts will be strong prior to implementation and during early usage, but will weaken over time as increasing direct experience with a system provides a growing basis for intentions towards continuous usage [36].

\subsubsection{Job Relevance}

One key constituent of the matching process discussed above is a potential user's judgment of job relevance, which was defined by [36] as an individual's perception regarding the degree to which the target system is appropriate to his or her job. In other words, job relevance is a function of the importance within one's job of the set of tasks the system is capable of supporting [36].

\subsubsection{Output Quality}

TAM2 hypothesizes that, over and above deliberations of what tasks a system is capable of performing and the degree to which those tasks match their job goals (job relevance), individuals of organizations will take into consideration how well the system performs those tasks, which is referred to as perceptions of output quality [36].

\subsubsection{Result Demonstrability}

It is possible that even effective systems can fail to garner user acceptance if individuals of organizations have difficulty attributing gains in their job performance specifically to their use of the system [36]. Therefore, TAM2 posits that result demonstrability, defined by Moore and Benbasat [41] as the "tangibility of the results of using the innovation," will directly influence perceived usefulness. This indicates that individuals can be expected to form more positive perceptions of the usefulness of a system if the co-variation between usage and positive results is readily achievable.

\subsection{Relevance of TAM2 to E-Business Adoption in the Hospitality Industry of Ghana}

In summary, TAM2 encompasses social influence processes (subjective norm, voluntariness, and image), job relevance, output quality, result demonstrability, and perceived ease of use as determinants of perceived usefulness and usage intentions. The theoretical concepts of TAM 2 described above are very important an essential for e-business adoption in the hospitality industry of Ghana. Individual workers in the hospitality industry of Ghana need to accept the use of technology and ICT in order for e-business to be successfully adopted. Non-acceptance of ICT usage will result in the failure of e-business adoption. After acceptance of technology and ICT, individual workers in the hospitality industry especially at top and middle management level have to adopt continuous usage of technology in order to sustain e-business. Vanketash and Davis [36] hypothesized that a decrease in the strength of the social influence processes affect perceived usefulness and intention to use. Therefore, for effective adoption of e-business in terms of initial and future technology usage, the hospitality industry in Ghana has to ensure that various workers within different organizations exhibit social influences through appropriate subjective norms, suitable voluntariness and favorable images within the organization.

As hypothesized by [36], various organizations within the hospitality industry of Ghana should monitor changes in social influence of their workers in order to gain direct experience from them so that e-business systems can be used continually and successfully. In terms of job relevance, if ebusiness adoption in an organization within the hospitality industry of Ghana doesn't relate or isn't relevant to the job functions of workers, there should be procedures established and adopted to make sure many relevant workers have job functions that are relevant to the e-business activities of the organization to ensure that the workers are capable of providing support to the e-business system. It is acknowledged that some workers may not be relevant to ebusiness, e.g. laborers and cleaners, however, organizations within the hospitality industry have to embark on the best possible ways to integrate such workers in e-business. Once job relevance is tackled, the hospitality industry in Ghana can adopt e-business in an easier and more effective way which will not worry/disturb various workers.

Additionally, if the output quality of e-business in the hospitality industry of Ghana doesn't match the job goals of individual workers in an organization, then the level of success pertaining to its adoption will be low. This is because e-business involves the performance of certain ICT tasks by individual workers in the hospitality industry of Ghana, and these tasks should reflect the job goals and relevance of individual workers. Furthermore, if the results of e-business adoption and usage demonstrate positively, then the perceptions of usefulness of e-business within the hospitality industry in Ghana will increase thus ensuring successful adoption of e-business.

\section{CONCLUSION}

Through relevant literature and an assessment of the Technology Acceptance Model 2 (TAM2), this paper presented a perception of e-business adoption in the hospitality industry of Ghana. The paper generally discussed e-business literature in relation to its evolution, concepts, models and adoption as well as e-business benefits and challenges. Additionally, the paper reviewed the hospitality industry in Ghana and further discussed how TAM2 is important for the adoption of e-business in the hospitality industry of Ghana. As a future work, this paper recommends that various organizations in the hospitality industry (such as Hotels) should assess and observe TAM2 as well as other relevant theories and frameworks in order to successfully adopt e-business systems and processes. Furthermore, the paper also recommends that organizations in the hospitality industry of Ghana should conduct thorough qualitative and quantitative research as well as pilot projects to ascertain their 
level of e-business adoption. This will help them know their current e-business state in order for them to proceed with adoption procedures cautiously.

\section{REFERENCES}

[1] N. Olifer and V. Olifer, "Computer Networks, Principles, Technologies and Protocol for Network Design," John Wiley and Sons Ltd, England, 2006.

[2] R. Baggio, "Information and Communication Technologies in the Hospitality Industry: the Italian Case," e-Review of Tourism Research (eRTR), Vol. 2, No. 5, pp. 108-114, 2004.

[3] N.Y. Asabere and V. Doku "Measuring Customer Relationship Management in the Hospitality Industry of Some Selected Hotels in Accra, Ghana: The Role of ICTs", International Journal of Application or Innovation in Engineering and Management (IJAIEM), Vol. 2, Issue 3, pp. 19-28, 2013.

[4] C. Ritchie, "Operating Systems: Incorporating UNIX and Windows", Continuum, London and New York. 4th Edition, 2003.

[5] B. M, Leiner, V.G. Cerf, D.D. Clark, R.E. Kahn, L Kleinrock, D.C. Lynch, J. Postel, L.G. Roberts, and, S. Wolff, "A Brief History of the Internet," $A C M$ SIGCOMM Computer Communication Review, Vol. 39, No. 5, 22-31, 2009.

[6] S. Greenstein, "Commercializing the Internet," IEEE Micro, Vol. 18, No.6, pp.6-7, 1998

[7] R. Amit and C. Zott, "Value Creation in E-Business," Strategic Management Journal, 22(6-7), pp. 493-520, 2001.

[8] T.R. Eikebrokk and D.H. Olsen, "An Empirical Investigation of Competency Factors Affecting EBusiness Success in European SMEs," Information \& Management, Vol. 44, No. 4, pp. 364-383, 2007.

[9] E.M. Daniel and H.N. Wilson, "The Role Of Dynamic Capabilities in E-Business Transformation," European Journal of Information Systems, Vol, 12, No. 4, pp. 282296, 2003.

[10] F. Damanpour, "E-business E-Commerce Evolution: Perspective and Strategy," Managerial Finance, Vol. 27, No. 7, pp. 16-33, 2001.

[11] M. Sigala, The Information And Communication Technologies Productivity Impact On The UK Hotel Sector, International Journal of Operations \& Production Management, Vol. 23, No. 10, pp. 12241245,2003

[12] V.B. Teye, "Tourism Development Experience in Ghana," DPMN Bulletin, Vol. 7, No. 1, pp. 8-12, 2000

[13] G.A. Bokpin and E.S. Nyarko, "Assessing The Corporate Governance Practices of the Hospitality Industry in Ghana," Investment Management and Financial Innovations Vol. 6, Issue 3, pp. 18-24, 2009.

[14] A Report on the Tourism Industry and the Ghanaian Economy, Research Department, Bank of Ghana, May 2007, Retrieved November 26, 2013 from http://www.bog.gov.gh/privatecontent/Research/Research\%20P apers/tourism.pdf

[15] J. Tallant, "E-Business Evolution," GRIN Verlag, 2011.

[16] J.D. Owens, "Electronic Business: A Business Model Can Make a Difference," Management Services, Vol. 50, No. 1, pp. 24-28, 2006.

[17] L.J. Zhang, J. Zhang, and, H. Cai, "E-Business Evolution," Services Computing, pp. 20-36, 2007.

[18] P. Baltzan, A. Phillips, K. Lynch and, Peter Blakey, "Business Driven Information Systems (BDIS)," Chapter 3, E-Business, McGraw-Hill, 2010.

[19] C. Dubelaar, A. Sohal, and V. Savic, "Benefits, Impediments and Critical Success Factors in B2C Ebusiness Adoption," Technovation, Vol. 25, No. 11, pp. 1251-1262, 2005.
[20] Definition of 'Success', "The Chambers Dictionary," Chambers-Harrap, Edinburgh, 1994.

[21] J.F. Rockart, "Chief Executives Define Their Own Data Needs," Haward Business Review. March-April, pp. 1528, 1979.

[22] V.K. Khandelwal, "An Empirical Study of Misalignment Between Australian CEOs and IT Managers," Journal of Strategic Information Systems, Vol. 10, pp. 15-28, 2001.

[23] P. Strassman, "The Information Payoff,". The Free Press, New York, 1985.

[24] M.E. Porter, "Strategy and the Internet," Harvard Business Review, pp. 62-78, 2001.

[25] L. Norton, "The e-business," Journal of Policy, Regulation and Strategy for Telecommunications Information and Media, 2 (5), pp. 449-454, 2000.

[26] A.S. Butler, "Developing Your Company's New Ebusiness," The Journal of Business Strategy, Vol. 21, No. 6, pp. 38-42, 2000.

[27] M.L Thorne, "Interpreting Corporate Ttransformation Through Failure," Management Decision, Vol. 38, No. 5, 2000.

[28] S. Bowde, D. Clark, P. Corner, J. Gibb, K. Kearins, and, K. Pavlovich, "Adoption and Implementation if Ebusiness in New Zealand: Preliminary Results," Proceedings of the $9^{\text {th }}$ Annual Conference of the New Zealand Strategic Management Society, 2000.

[29] R. M. Kanter, “The Ten Deadly Mistakes of Wanna-dots" Hardvard Business Review, pp. 91-100, January 2001.

[30] A. Barua, P. Konana, A.B. Whinston, and, F. Yin, "Driving E-business Excellence.," MIT Sloan Management Review, Vol. 43, No. 1, pp. 36-44, 2001.

[31] A. Slywotzky and D. Morisson, "Becoming a Digital Business: It's Not About Technology,". Strategy and Leadership, Vol. 29, No. 2, pp. 4-9, 2001.

[32] J.A. Rodgers, D.C. Yen, D.C. Chou, "Developing Ebusiness: A Strategic Approach," Information Management and Computer Security, Vol. 10, No. 4, pp. 184-192, 2002.

[33] National Tourism Development Plan (2013-2027), Republic of Ghana, Retrieved November 27, 2013 from http://www.ghana.travel/info/downloads/gtdp.pdf

[34] I. Issahaku, "Adoption of E-Business in the Hospitality Industry in Ghana - A Case Study of Hotels", Commonwealth Executive Masters of Business Administration (CEMBA) Thesis, Kwame Nkrumah University of Technology (KNUST), Kumasi, Ghana, April 2012

[35] F.D. Davis, "Perceived Usefulness, Perceived Ease of Use, and User Acceptance of Information Technology. MIS Quart., Vol. 13, pp. 319-339, 1989.

[36] V. Venkatesh and F.D. Davis, "A Theoretical Extension of the Technology Acceptance Model: Four Longitudinal Field Studies," Management Science, Vol. 46, No. 2, pp. 186-204, 2000.

[37] D.E. Sichel, "The Computer Revolution: An Economic Perspective," The Brookings Institution, Washington, DC, 1997.

[38] V. Venkatesh, "Creation of Favorable User Perceptions: Exploring the Role of Intrinsic Motivation," MIS Quart., Vol. 23, pp. 239-260, 1999.

[39] M.. Fishbein and I. Ajzen., "Belief, Attitude, Intention and Behavior: An Introduction to Theory and Research," Addison-Wesley, Reading, MA, 1975.

[40] H.C. Kelman, "Compliance, Identification, and Internalization: Three Processes of Attitude Change,". Journal of. Conflict Resolution (2) pp. 51-60, 1958.

[41] G.C. Moore and I. Benbasat, "Development of an Instrument to Measure the Perceptions of Adopting an Information Technology Innovation," Inform. Systems Res. (2), pp.192-222, 1991. 